\title{
The imageability effect in good and poor readers
}

\author{
ANNE E. KLOSE, STEVEN SCHWARTZ, and JUDITH W. M. BROWN \\ University of Queensland, St. Lucia, Brisbane, Queensland, Australia
}

\begin{abstract}
The "imageability effect"-highly imageable words are easier to read than abstract wordshas been found in cases of acquired dyslexia, developmental dyslexia, and even normal readers. The hypothesis that the imageability effect is a function of the differing ages at which imageable and abstract words are acquired was examined in the present experiment. Specifically, it was hypothesized that if the imageability effect is actually mediated by age of acquisition, then equating high- and low-imagery words for age of acquisition should eliminate the effect. Good and poor readers were required to indicate whether high- and low-imagery words (equated for age of acquisition) were identical to previously presented words and to indicate their confidence in their judgment. Good and poor readers did not differ in their ability to recognize formerly presented high- or low-imagery words. Subjects were also asked to read the words aloud. Reading latency was unaffected by word imagery for either reading group. It was concluded that the imageability effect is mediated by age of acquisition and that controlling this factor eliminates the effect.
\end{abstract}

Acquired dyslexia-reading disability caused by brain damage-can take several forms (See Patterson, 1981, for a review). Perhaps the most carefully studied syndrome is deep dyslexia (Shallice \& Warrington, 1975). Although there is some controversy about whether deep dyslexia actually constitutes a unitary syndrome (Henderson, 1981), one finding appears to be reliable. Patients identified as deep dyslexics have difficulty reading words rated low in imageability (Marshall \& Newcombe, 1973; Patterson \& Marcel, 1977; Richardson, 1975; Shallice \& Warrington, 1975).

Greater difficulty in reading abstract than in reading highly imageable words is not a characteristic unique to deep dyslexics. For example, Jorm (1977) found that reading-disabled children (sometimes called "developmental dyslexics") also find it easier to read imageable than to read abstract words. Baddeley, Ellis, Miles, and Lewis (1982), in a study designed to examine similarities between reading-disabled children and deep dyslexics, found that even normal readers show the "imageability effect."

It is not self-evident why imageable words should be easier to read than abstract words, but one possibility may lie in their respective ages of acquisition. Baddeley et al. (1982) (following Marshall, Newcombe, \& Holmes, 1975) hypothesized that high-imageability words are learned earlier than abstract ones, thereby making them

This research was supported by grants from the Australian Research Grants Committee, the Educational Research and Development Committee, and the University of Queensland Special Projects fund to the second author. Reprint requests should be sent to Steven Schwartz, Department of Psychology, University of Queensland, St. Lucia, Queensland 4067, Australia. more available to both good and poor readers. This hypothesis is supported by Gilhooly and Logie's (1981) finding that, among normal adult readers, retrieving word meanings from lexical memory is faster for earlyacquired words than for words learned later in life.

If the imageability effect is actually mediated by age of acquisition, then equating high- and low-imageability words for age of acquisition should lead to the disappearance of the effect. This was the hypothesis investigated in the present study. Should the imageability effect continue to be present even after words are equated for age of acquisition, it is important to determine what other mechanism may be responsible for making highly imageable words easier to read. The present research tried to distinguish between word readability (high-imagery words are inherently easier to read) and response bias (high-imagery words have a lower response criterion) as explanations for the imageability effect. Signal-detection measures were used to distinguish between these two possibilities.

\section{METHOD}

\section{Subjects}

Forty-three teenage male volunteers served as subjects in this study. All subjects were initially assessed with the GAPADOL Reading Comprehension Test (McLeod \& Anderson, 1972) and the nonverbal battery of the Lorge-Thorndike Intelligence Test (Lorge, Thorndike, \& Hagen, 1964). The GAPADOL is a cloze test requiring subjects to complete six passages by filling in missing words. The passages are designed to be of increasing difficulty, and the instrument has been standardized on the Australian population. The 11 highest and 11 lowest scoring subjects on the GAPADOL constituted the good and the poor reading groups, respectively. The two groups had means indicating an average 2 -year difference in reading age. This difference was statistically significant $[t(20)=12.38, p<.01]$. The two groups were not significantly different in nonverbal IQ. 


\section{Apparatus and Setting}

Stimulus presentation and response collection were controlled by a Cromemco Z-2D computer. The instructions and stimuli were presented on a Televideo 912 video display terminal. A console containing an orange button and a black button was placed on a table in front of the terminal. The subjects participated singly in a quiet room. Forty high- and 40 lowimageability stimulus words were used in the study. These words were taken from those used by Gilhooly and Logie (1980). Although the words differed in imageability $[\mathrm{t}(78)=$ $22.98, \mathrm{p}<.001$ ], they did not differ in concreteness, age of acquisition, length, or frequency, according to the norms published by Gilhooly and Logie (1980).

\section{Procedure}

The subjects were introduced to the apparatus and told that they would be seeing words on the video display screen. They were told that the first word would disappear quickly and be replaced by another word. If they were certain the second word was identical to the first, the subjects were to push the " 0 " on the terminal keyboard. If they were certain the word was not the same as the previous one, they were to push the " 9 " button. Responses between 0 and 9 indicated varying degrees of confidence in their judgment. The subjects were cautioned to be as accurate and as fast as possible. The first words were presented for $50 \mathrm{msec}$, followed by a delay of $100 \mathrm{msec}$ before the second word appeared. Twenty practice trials preceded the 80 experimental trials. All possible combinations of low- and high-imageability words were presented. The experimental trials consisted of 30 high-imageability word pairs and 30 lowimageability word pairs (one-third of these were mismatches; the rest were matches). There were also 20 presentations in which high- and low-imageability words were paired (naturally, all of these were mismatches). The subjects received the various pairs in different random orders.

Upon the completion of the experiment, the subjects were fitted with a throat microphone attached to the computer. They were then asked to read each stimulus word aloud as it appeared on the terminal screen. Reading latency (the delay between the presentation of the word and the initiation of a vocalization) was recorded by the computer from the throat microphone. The subjects were given 20 practice trials on a separate set of words and then the 80 words used in the previous task. The task was self-paced. Each subject indicated readiness for another trial by pushing the orange button on the console. This also activated the microphone, which was inactive between trials. Word-presentation order was randomized across subjects.

\section{RESULTS AND DISCUSSION}

Both good and poor subjects made very few errors in the task requiring them to identify whether a word had been previously presented. The mean false-alarm rate (indicating the words were identical when they were not) was slightly greater among poor than among good readers $(15 \%$ vs. $10 \%)$, but this difference was not statistically significant. More important for our present purposes is that the false-alarm rate was the same for both high- and low-imageability words in both reading groups. That is, the subjects in both reading groups were no more likely to misrecognize a high-imagery than a low-imagery word.

Signal-detection statistics $\mathrm{d}^{\prime}$ and beta were calculated using the method described by Hochhaus (1972). This was done separately for high- and for low-imageability words in each condition. The statistic d', which is a measure of sensitivity or, in this case, the inherent readability of words, averaged 3.53 for the high- and 3.93 for the low-imageability words among the good readers. Among the poor readers, the mean $\mathrm{d}^{\prime}$ for highimageability words was 3.53 , and the mean $\mathrm{d}^{\prime}$ for lowimageability words was 3.44 . Neither the difference between high- and low-imageability words nor the differences between reading groups were statistically significant. Beta, a statistic that is supposed to reflect bias in responding, was also calculated for each type of word separately in each group. Among the good readers, the mean betas for high- and low-imageability words were 2.77 and 1.41 , respectively. Among poor readers, these betas were 2.77 and 1.75 , respectively. If anything, there appears to be a bias in these figures that favors low-imagery rather than high-imagery words. However, the differences in beta also did not reach statistical significance.

There appears to be little evidence in this task for an imageability effect. Neither error rates nor statistics derived from signal-detection theory discriminate between high- and low-imagery words. It would appear that equating these words for age of acquisition has, as predicted, eliminated the effect. The second task-having the subjects read each word aloud while response latencies were recorded-was designed as a check on the results of the first task. The mean response latencies for the good readers was $675 \mathrm{msec}$ for the high-imageability words and $690 \mathrm{msec}$ for the low-imageability words. For the poor readers, the means were 743 and 729 msec for the high- and low-imageability words, respectively. A two-way analysis of variance of these data produced no significant effects. Although the poor readers were somewhat slower than the good readers, neither this difference nor the difference between highand low-imagery words was statistically significant. This finding merely supports the results of the earlier task.

Although it appears that controlling words for age of acquisition eliminates the imageability effect, the mechanism by which age of acquisition operates was not clarified in this study. This is because age of acquisition was held constant rather than allowed to vary. One possibility is that there is a response bias toward earlier learned words. Another possibility is that words learned earlier are actually inherently easier to read. Further research (perhaps using signal-detection measures), in which age of acquisition is permitted to vary, may serve to distinguish between these two possibilities.

\section{REFERENCES}

Baddeley, A. D., Ellis, N. C., Miles, T. R., \& Lewis, V. J. Developmental and acquired dyslexia: A comparison. Cognition, 1982, 11, 185-199.

Gilhooly, K. J., \& Logie, R. H. Methods and designs: Age of acquisition, imagery, concreteness, familiarity, and ambiguity measures for 1,944 words. Behavior Research Methods \& Instrumentation, 1980, 12, 395-427. 
Gilhooly, K. J., \& Logie, R. H. Word age-of-acquisition, reading latencies and auditory recognition. Current Psychological Research, 1981, 1, 251-262.

HENDERSON, L. Critical notice: Information-processing approaches to acquired dyslexia. Quarterly Journal of Experimental Psychology, 1981, 33, 507-522.

Hochraus, L. A table for the calculation of $\mathrm{d}^{\prime}$ and beta. Psychological Bulletin, 1972, 77, 375-376.

JoRM, A. F. Effects of word imagery on reading performance as a function of reader ability. Journal of Educational Psychology, $1977,69,46-54$

LoRge, I., Thorndike, R. L., \& HAGen, E. The Lorge-Thorndike Intelligence Test. Boston: Houghton Mifflin, 1964.

Marshall, J. C., \& Newcombe, F. Patterns of paralexia: A psycholinguistic approach. Journal of Psycholinguistic Research, 1973, 2, 175-199.

Marshall, J. C., Newcombe, F., \& Holmes, J. M. Lexical memory: A linguistic approach. In A. Kennedy \& A. Wilkes (Eds.), Studies in long-term memory. London: Wiley, 1975.

McLeod, J., \& Anderson, J. GAPADOL Reading Comprehension Test. Melbourne: Heinemann Educational Australia, 1972.

Patterson, K. Neuropsychological approaches to the study of reading. British Journal of Psychology, 1981, 72, 151-174.

Patterson, K., \& Marcel, A. J. Aphasia, dyslexia and the phonological coding of written words. Quarterly Journal of Experimental Psychology, 1977, 29, 307-318.

Richardson, J. T. E. The effect of word imageability in acquired dyslexia. Neuropsychologica, 1975, 13, 1-7.

Shallice, T., \& Warrington, E. K. Word recognition in a phonemic dyslexia patient. Quarterly Journal of Experimental Psychology, 1975, 27, 187-199.

(Manuscript received for publication August 29, 1983.) 